\title{
Nasal Septum Perforation due to Cocaine Abuse
}

\author{
Ballage A*, El Harti M, Naceur S, Rouadi S, Abada RL, Roubal M and Mahtar M \\ Department of ENT, 20 Aout Hospital, Ibn Rochd University Hospital, Casablanca, Morocco
}

*Corresponding author: Ballage A, Department of ENT, 20 Aout Hospital, Ibn Rochd University Hospital, Casablanca, Morocco, E-mail: amineballage19@gmail.com

Citation: Ballage A, El Harti M, Naceur S, Rouadi S, Abada RL, et al. (2017) Nasal Septum Perforation due to Cocaïne Abuse. SAJ Case Rep 4: 302

Article history: Received: 13 May 2017, Accepted: 05 July 2017, Published: 07 July 2017

\begin{abstract}
Introduction: Differences in the effect of cocaine based on the route of administration have been an interest of researchers and clinicians for the past few decades. Intranasal administration of the powder form of cocaine (cocaine hydrochloride) was most popular.

Perforation of the nasal septum is an uncommon condition, When it occurs its cause is most often idiopathic or traumatic. Nasal septum perforation may also be the presenting sign of drug addiction. In this article, we describe a case of nasal septal perforation secondary to cocaine intranasal abuse. We also briefly review other common causes of perforation of the nasal septum.

Case Report: This report describes the case of a 56-year-old man who was addicted to cocaine while 10 years and who presented with perforation of the nasal septum.

The patient reported that he had always snorted through the right nostril. There was no history of trauma and no somatic or psychiatric troubles.

In an endoscopic examination a large septal perforation accompanied by excessive necrotic tissues in the nasal space was obvious.

Conclusion: Patient history and assurance regarding illegal drug consumption and abuse is a key point for fast and accurate diagnosis. The pathophysiology of drug-induced sinunasal disease differential diagnoses, treatment are discussed.
\end{abstract}

Keywords: Cocaine Hydrochloride; Intranasal Administration; Perforation

\section{Introduction}

Cocaine is an alkaloid, which was originally used by South American Indians as a stimulant. It was introduced to medicine by Köller in the 1880s as a local anaesthetic. More recently, its stimulant effects have led to its use as a recreational drug resulting in social, economic and physical harm [1].

Differences in the effect of cocaine based on the route of administration have been an interest of researchers and clinicians for the past few decades. Intranasal administration of the powder form of cocaine (cocaine hydrochloride) was most popular [2].

Perforation of the nasal septum is an uncommon condition; Classically, this type of necrosis has been linked to cocaine intranasal use [3]. When it occurs, its cause is most often idiopathic or traumatic. Nasal septum perforation may also be the presenting sign of drug addiction or a potentially life-threatening or serious systemic illness, even in an asymptomatic patient [1,4-7]. In this article, we describe a case of nasal septal perforation secondary to cocaine intranasal abuse. We also briefly review other common causes of perforation of the nasal septum.

\section{Case Report}

A 56-year-old man presented with nasal congestion, and nasal obstruction. The symptoms were reported to have started only 5 months earlier. he gave a ten years history of nasal cocaine usage, initially at a frequency of two to three times a month but developing into a daily habit. 
The patient reported that he had always snorted through the right nostril. There was no history of trauma and no somatic or psychiatric troubles.

On examination her nasal cavities were filled with necrotic debris and extremely sensitive to touch, no deformity in the form of nose was observed. The soft palate, hard palate, tonsils and posterior oropharyngeal wall were normal.

In an endoscopic examination a large septal perforation accompanied by excessive necrotic tissues in the nasal space was obvious (Figure 1 and 2).
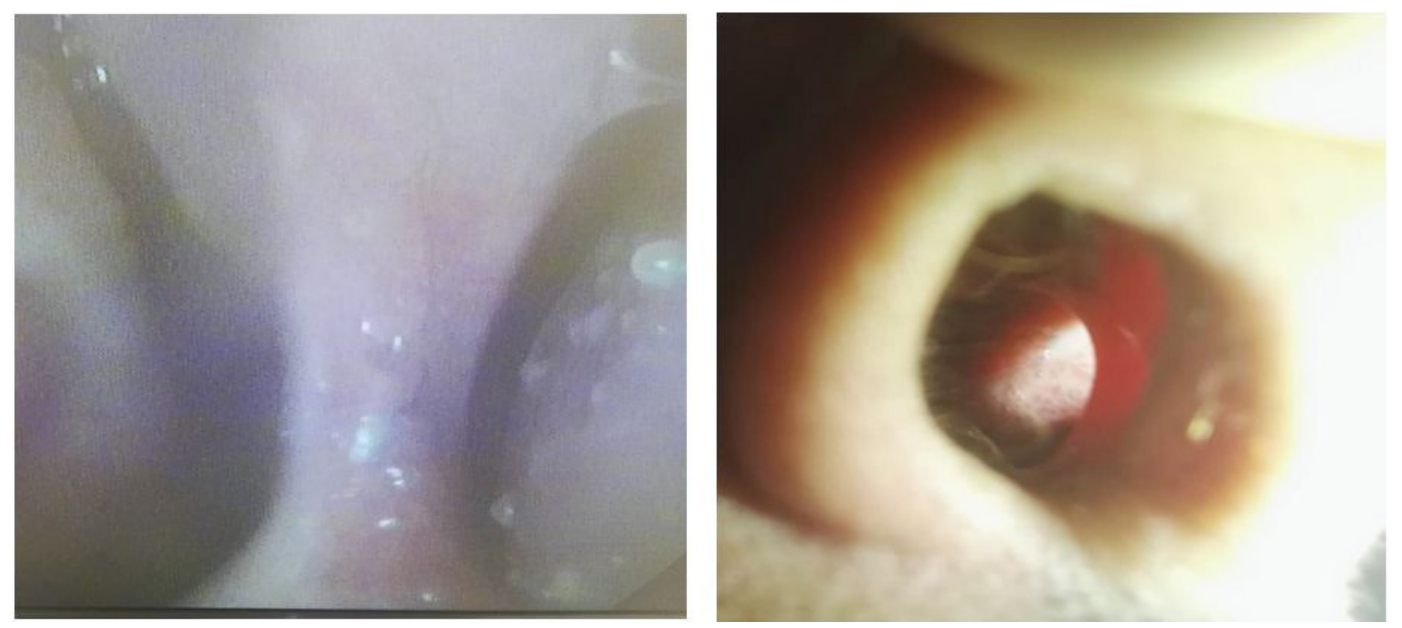

Figure 1 and 2: Endoscopic view of the patient's nasal cavity

Multiple biopsies of the nose and palate were taken and showed necrosis and ulceration with signs of inflammation but no evidence for vacuities or granulomatosis.

A CT scan of the paranasal sinus showed necrosis of the nasal septum (Figure 3).

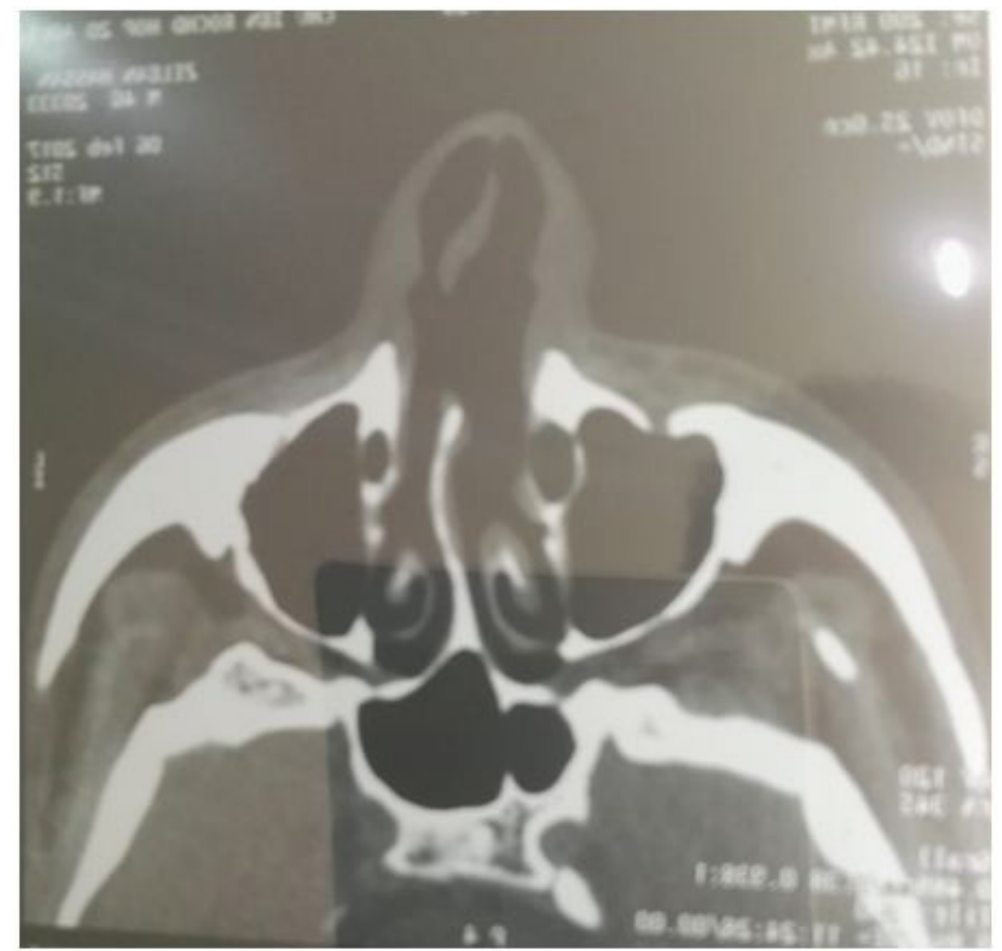

Figure 3: Radiologic view of the patient's paranasal sinus

\section{Discussion}

Intranasal drug abuse appears to be a growing trend. In addition to cocaine, insufflation of heroin and other opioids, stimulants, benzodiazepines, has been reported [8-10]. Among heroin abusers, insufflation has become a popular method of drug administration, with rates of injection of heroin declining dramatically [11,12]. This shift toward intranasal administration may be due in part to increasing awareness of HIV among drug abusers [13,14]. 
Erosion of the soft palate and nasal turbinates are more recently reported complications of intranasal prescription narcotic abuse [15].

Xerostomia and septal perforation were discernible in the patient in this case.

Though palatal perforations and destructive orofacial lesions are uncommonly seen in abusers of drugs other than cocaine, clinicians should be aware that a variety of causative agents and pathologic conditions may be associated with this clinical presentation [16$18]$.

Cocaine induces vasoconstriction and might cause necrosis in the mucosae and surrounding tissues (cartilaginous and osseous). Frequent contact induces nasal septal destruction, choanae, paranasal sinus walls and palatine [13,19].

Ulcerative lesions affecting the midface were considered for differential diagnosis including traumatic, infectious and neoplasic, such as Wegener's granulomatosis, nasal NK/T cell lymphoma and mucormycosis. Though unfrequent rhinoscleroma and other lymphomas must be also considerer [13]. In 2 of the 3 previously reported cases of destructive lesions resulting from intranasal prescription narcotic abuse, patients were found to have invasive fungal rhinosinusitis [20,21]. This finding is absent in our case and is somewhat surprising, because invasive fungal rhinosinusitis is typically exclusive to immune-compromised individuals [22].

\section{Conclusion}

Patient history and assurance regarding illegal drug consumption and abuse is a key point for fast and accurate diagnosis. Furthermore, each attempt to clarify the drug type and route of consumption leads to prevention of this unwanted complication [23]. We can conclude that intranasal cocaine abuse can induce necrosis and focal ischemia that causes secondary mucosa and midfacial bone destruction, and must be differentiated from aggressive neoplasias, inflammatory or infectious processes.

\section{References}

1. Messinger E (1962) Narcotic septal perforations due to drug addiction. JAMA 179: 964-5.

2. Kiluk BD, Babuscio TA, Nich C, Carroll KM (2013) Smokers versus snorters: do treatment outcomes differ according to route of cocaine administration? Exp Clin Psychopharmacol 21: 490-8.

3. Hardison SA, Marcum KK, Lintzenich CR (2015) Severe necrosis of the palate and nasal septum resulting from intranasal abuse of acetaminophen. Ear Nose Throat J 94: E40-2.

4. Neville B, Damm DD, Allen C, Bouquot J (2002) Physical and chemical injuries. In: Neville BW, Damm DD, Allen CM, Bouquot JE, editors. Oral and maxillofacial pathology. 2nd ed. Philadelphia Saunders 259-61.

5. Helie F, Fournier J (1997) Destructive lesions of the median line secondary to cocaine abuse. J Otolaryngol 26: 67-9.

6. Vasica G, Tennant CC (2002) Cocaine use and cardiovascular complications. Med J Aust 177: 260-2.

7. Linder JD, Mönkemüller KE, Raijman I, Johnson L, Lazenby AJ, et al. (2000) Cocaine-associated ischemic colitis. South Med J 93: 909-13.

8. Jouary T, Bens G, Lepreux S, Buzenet C, Taieb A (2003) Cocaine-related localized necrotic livedo. Ann Dermatol Venereol 130: 537-40.

9. Schultz JE, Gross GJ (2001) Opioids and cardioprotection. Pharmacol Ther 89: 123-37.

10. Sheehan MF, Sheehan DV, Torres A, Coppola A, Francis E (1991) Snorting benzodiazepines. Am J Drug Alcohol Abuse 17: 457-68.

11. Frank B (2000) An overview of heroin trends in New York City: past, present and future. Mt Sinai J Med 67: 340-6.

12. Schwartz RH (1998) Adolescent heroin use: a review. Pediatrics 102: 1461-6.

13. Seyer BA, Grist W, Muller S (2002) Aggressive destructive midfacial lesion from cocaine abuse. Oral Surg Oral Med Oral Pathol Oral Radiol Endod 94: 465-70.

14. Cottrell DA, Mehra P, Malloy JC, Ghali GE (1999) Midline palatal perforation. J Oral Maxillofac Surg 57: 990-5.

15. Yewell J, Haydon R, Archer S, Manaligod JM (2002) Complications of intranasal prescription narcotic abuse. Ann Otol Rhinol Laryngol 111: 174-7.

16. Deutsch HL, Millard DR (1989) A new cocaine abuse complex. Involvement of nose, septum, palate, and pharynx. Arch Otolaryngol Head Neck Surg 115: 235-7.

17. Vilensky W (1982) Illicit and licit drugs causing perforation of the nasal septum. J Forensic Sci 27: 958-62.

18. Owens WD (1912) Signs and symptoms presented by those addicted to cocaine: observations in a series of twenty-three cases. JAMA 58: 329-30.

19. Tubaro E, Borelli G, Croce C, Cavallo G, Santiangeli C (1983) Effect of morphine on resistance to infection. J Infect Dis 148: 656-66.

20. Rouveix B (1992) Opiates and immune function. Consequences on infectious diseases with special reference to AIDS. Therapie 47: 503-12.

21. Carr DJ, Rogers TJ, Weber RJ (1996) The relevance of opioids and opioid receptors on immunocompetence and immune homeostasis. Proc Soc Exp Biol Med 213: 248-57.

22. Lund VJ, Lloyd G, Savy L, Howard D (2000) Fungal rhinosinusitis. J Laryngol Otol 114: 76-80.

23. Peyrière H, Léglise $\mathrm{Y}$, Rousseau A, Cartier C, Gibaja V, et al. (2013) Necrosis of the intranasal structures and soft palate as a result of heroin snorting: a case series. Subst Abus 34: 409-14. 